\title{
CONGENITAL HIGH AIRWAY OBSTRUCTION (CHAOS) SYNDROME: A RARE CASE PRESENTATION
}

\author{
Dinakara Prithviraj ${ }^{1}$, Suresh $A^{2}$, Anna Mariam Paul ${ }^{3}$
}

\section{HOW TO CITE THIS ARTICLE:}

Dinakara Prithviraj, Suresh A, Anna Mariam Paul. "Congenital High Airway Obstruction (Chaos) Syndrome: A Rare Case Presentation". Journal of Evolution of Medical and Dental Sciences 2014; Vol. 3, Issue 17, April 28; Page: 4710-4717, DOI: $10.14260 /$ jemds/2014/2500

ABSTRACT: Congenital high airway obstruction syndrome (CHAOS) results in a predictable constellation of findings: large echogenic lungs flattened or inverted diaphragms, dilated airways distal to the obstruction, and fetal ascites and/or hydrops. ${ }^{1}$ The finding of CHAOS on prenatal ultrasound examination is diagnostic of complete or near-complete obstruction of the fetal upper airway, most likely caused by laryngeal atresia. A greater understanding of the natural history of CHAOS may permit improved prenatal and perinatal management.

KEYWORDS: Laryngeal atresia; Tracheal stenosis; fetal hydrops; Fraser syndrome; fetal surgery.

INTRODUCTION: Congenital chest malformations are rare, and may involve the lung parenchyma, bronchi, arterial supply, and venous drainage. They include congenital cystic adenomatoid malformation (CCAM), congenital diaphragmatic hernia (CDH), bronchopulmonary sequestration (BPS), congenital hydrothorax, and congenital lobar emphysema. Rarer entities include congenital high airway obstruction syndrome (CHAOS), congenital bronchogenic cyst, bronchial atresia, pulmonary Arterio Venous malformation (PAVM), congenital pulmonary lymphangiectasia, pulmonary hypoplasia-aplasia, mediastinal teratoma, and mediastinal lymphangioma. ${ }^{2}$

Sometimes there may be compromise in normal pulmonary development, causing hypoplastic lung formation. Pulmonary abnormalities are not mutually exclusive, since abnormalities frequently occur together as hybrid conditions.

MATERIALS AND METHODS: Here we present a case of a fetus post-delivery found to have large hyperechoic lungs, flattened diaphragm and hydrops in the prenatal scan, which form a triad in the detection of CHAOS.

A brief review of literature is discussed.

CASE PRESENTATION: In our case we had a twenty six years old pregnant lady with twenty two weeks history of amenorrohea who had come for a routine antenatal scan. She was the mother of a two year old child which was born normally and was doing well. On antenatal ultrasound of the present pregnancy, the fetus was found to be of approximately twenty weeks gestation. The fetus was found to have large hyperechoic lungs, flattened diaphragm and hydrops which form a triad in the detection of CHAOS. (Fig. 1)

The patient and her husband were counseled regarding the risks involved on progression of the fetus till birth. The parents agreed to terminate the pregnancy voluntarily.

A dead male fetus was delivered and sent for autopsy subsequently. An interesting finding noted during dissection of neck and thoracic organs was an abrupt ending of the trachea approximately $11 \mathrm{~mm}$ caudal to the lower end of larynx. (Fig. 2 \& Fig. 3).

The subsequent histopathology showing swollen cells confirmed the diagnosis (Fig. 4) 
DISCUSSION: Congenital high airway obstruction syndrome (CHAOS) was defined by Hedrick et al in 1994 as upper airway obstruction that is diagnosed in utero by ultrasound, with concomitant findings of large echogenic lungs, flattened or inverted diaphragms, and dilated airways distal to the obstruction, and fetal ascites or hydrops.

CHAOS is a rare abnormality with a poor prognosis and is caused by complete or nearcomplete obstruction of the fetal airway, leading to the trapping of lung fluids, hyperplasia of pulmonary alveoli, and tracheal dilatation. ${ }^{3}$

Fetuses with CHAOS may develop hydrops due to cardiac compression and obstructed venous return.

Airway abnormalities and lesions presenting as congenital high airway obstruction syndrome at birth are Laryngeal atresia, Laryngeal stenosis, Laryngeal cyst, Laryngeal web, Tracheal stenosis and Tracheal atresia. ${ }^{4}$

INCIDENCE: Only fifty two cases have been reported with twenty two of these cases reported since 1989; though the true incidence may be higher than suggested by these case reports. A genetic cause or predisposition for CHAOS has not been determined. ${ }^{5}$

Vanhaesebrouck et al in 2006_reported a unique family with autosomal dominant inheritance of CHAOS and variable expression in the affected father and two affected children. The father had a history of being treated for "chronic croup" by tracheal cannulation. The father underwent an indirect laryngoscopy, after his child's presentation with CHAOS, which revealed partial subglottic webbing suggesting that the father was also mildly affected by CHAOS. ${ }^{6}$

They concluded that minor expression in one of the parents may be an important indicator for genetic counseling in CHAOS and management of future pregnancies.

PATHOPHYSIOLOGY: In the human, the first signs of laryngeal development are apparent in the fourth gestational week, with the development of a laryngotracheal groove on the ventral surface of the caudal end of the pharynx. This groove progressively deepens to form a diverticulum anterior to the pharynx. The distal portion of this diverticulum will eventually enlarge to form a lung bud. Proximally, the lateral walls of the diverticulum invaginate to form tracheoesophageal folds, which eventually fuse in the midline.

This fusion forms a tracheoesophageal septum, which separates the primitive airway from the pharynx and esophagus. The cartilaginous structures of the larynx are derived from the fourth and sixth pairs of branchial arches and begin their development in the fifth week of gestation. Arytenoid swellings form at the laryngeal inlet, narrowing the slit like aperture. The embryological development of the glottis has been a subject of controversy in the past.

Today, there is agreement that the glottic epithelium proliferates, rapidly forming a temporary occlusion of the laryngeal lumen. This plug is recanalized by the tenth week of fetal life. Throughout this phase of laryngeal development, a posterior communication between the primitive trachea and the foregut remains patent as the pharyngoglottic duct. ${ }^{7}$

In 1965, Smith and Bain reported nine of their own cases of laryngeal atresia and reviewed twenty one more from the literature. Using these cases, the author's categorized laryngeal atresia into three types, depending on the location of the deformity. ${ }^{8}$ Later work by Zaw-Tun suggested that these three types of atresia may represent arrests at specific periods of development. Therefore, CHAOS has 
three possible presentations: (1) complete laryngeal atresia without an esophageal fistula, (2) complete laryngeal atresia with a TEF, and (3) near complete high upper airway obstruction. ${ }^{9}$

ANTENATAL DETECTION: The findings observed on prenatal ultrasound are thought to be a result of upper airway obstruction, which prevents the normal flow of fetal lung fluid into the amniotic fluid. ${ }^{10}$ The lungs therefore expand and produce a flattening of the diaphragm and appear hyper echogenic on ultrasound; if the lung fields expand to the point of producing esophageal compression, polyhydramnios may occur as a result of impaired swallowing of amniotic fluid.

The fundamental pathophysiology of CHAOS is altered when there is either an incomplete upper airway obstruction or a tracheoesophageal fistula (TEF), as the fetal lung fluid now has a way to flow from the pulmonary system, and the lung fields therefore do not expand outward. In utero ultrasound may therefore not diagnose the impending danger due to the upper airway obstruction.

Type three CCAM (congenital cystic adenomatoid malformation) is one of the differential diagnoses for CHAOS. ${ }^{11}$

ASSOCIATED ANOMALIES: The most frequently associated syndrome observed with CHAOS is Fraser syndrome which is characterized by malformations of the larynx, cryptophthalmos, syndactyly, genitourinary tract, craniofacial dysmorphism, orofacial clefting, mental retardation, and musculoskeletal anomalies. Other syndromes that have been reported in association with CHAOS include: Short-rib polydactyly syndrome, Cri-du-Chat syndrome and Velo-Cardio-Facial syndrome. Recently CHAOS has been described as part of a newly proposed association, TACRD (Tracheal Agenesis, complex congenital Cardiac abnormalities, Radial ray defects, and duodenal atresia) pattern. ${ }^{12}$

NEWER CHALLENGES: Prenatally, fetoscopic tracheoscopy has been performed to delineate and treat the cause of obstruction. A favorable outcome following in utero ultrasound-guided decompression of the fetal trachea was recently reported in an infant with CHAOS from laryngeal atresia.

At delivery, the management of prenatally diagnosed CHAOS requires the presence of a multidisciplinary team including: neonatologists, pediatric otorhinolaryngologist, and pediatric surgeons. ${ }^{13}$

The EXIT procedure (ex utero intrapartum treatment), which was first developed for reversing tracheal occlusion in fetuses with severe congenital diaphragmatic hernia, offers the advantage of ensuring uteroplacental gas exchange while on placental support and has resulted in favorable outcome in some cases of prenatally diagnosed CHAOS.

CCAM volume ratio $=$ [mass length $($ in $\mathrm{cm}) \times$ mass height $($ in $\mathrm{cm}) \times$ mass width $($ in $\mathrm{cm}) \times 0.52]$

$$
\text { Fetal HC (in cm) }
$$

CCAM volume ratio identifies fetuses at high risk for developing hydrops.

CVR greater than 1.6 is associated with an $80 \%$ risk of developing hydrops.

Neonatal survival approaches $100 \%$ in the absence of hydrops. 


\section{CASE REPORT}

\section{ANTENATAL ULTRASOUND IMAGES (Fig. 1, 1-3)}

Fig. 1.1: ANTENATAL ULTRASOUND OF FETUS, REVEALING ENLARGED THORAX WITH HYPERECHOGENIC SOLIDIFIED LUNGS \& HYPOECHOGENIC COLLECTION SUGGESTIVE OF ASCITIS.

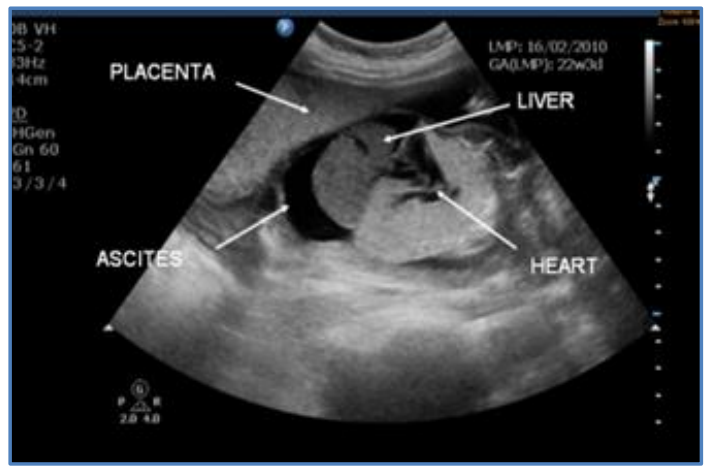

\section{Figure 1.1}

Fig. 1.3: REVEALING PROTRUBERANT THORAX WITH SOLIDIFIED HYPERECHOGENIC LUNGS \& ASCITIES.

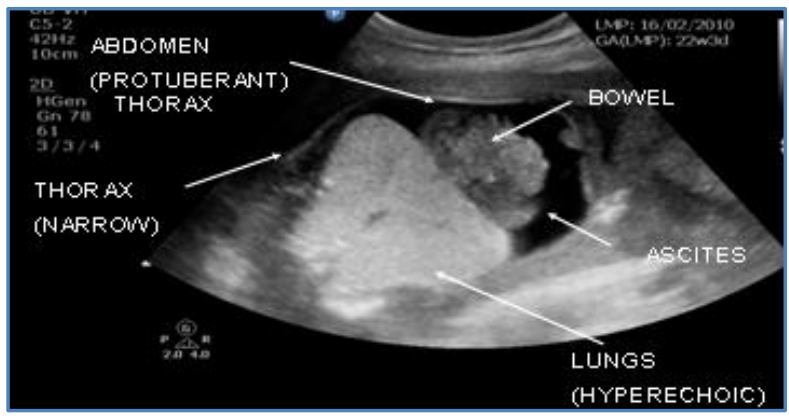

\section{Figure 1.3}

\section{IMMEDIATELY AFTER BIRTH (Fig: 2, 1-3)}

Fig. 2.1: PHOTOGRAPH SHOWING EDEMATOUS FACE

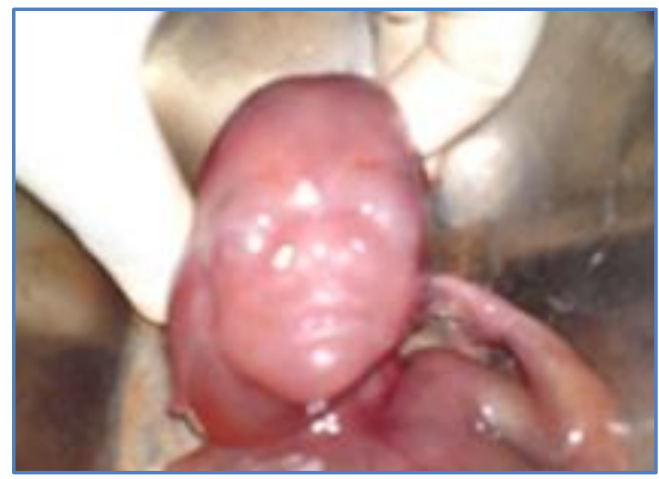

Figure 2.1 


\section{CASE REPORT}

Fig. 2.2: PHOTOGRAPH SHOWING DISTENDED CHEST \&ABDOMEN WITH FULLNESS OF FLANKS \& ENGORGED SUPERFICIAL VEINS.

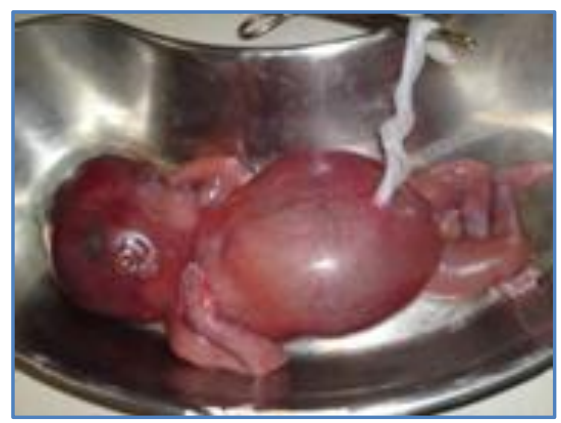

Figure 2.2

Fig. 2.3: PHOTOGRAPH SHOWING THE EDEMATOUS FACIES WITH PROTRUBERANT ABDOMEN.

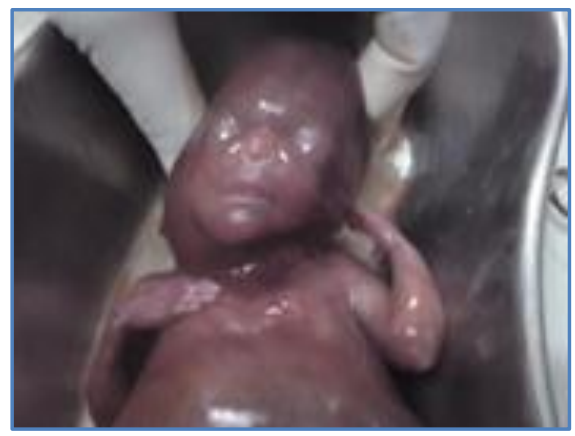

Figure 2.3

\section{AUTOPSY IMAGES (Fig: 3, 1-5)}

Fig. 3.1: PHOTOGRAPH SHOWING THE FETUS WITH PROTRUBERANT ABDOMEN \& EXPELLED PLACENTA.

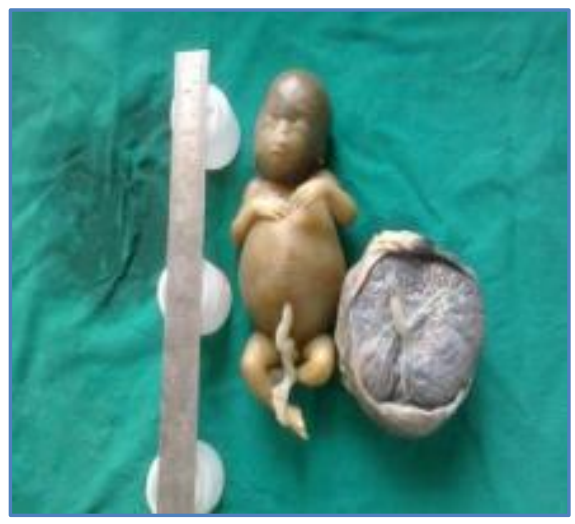

Figure 3.1 


\section{CASE REPORT}

Fig. 3.2: PHOTOGRAPH SHOWING INCISED CHEST AND ABDOMINAL WALL WITH SOLIDIFIED LUNGS.

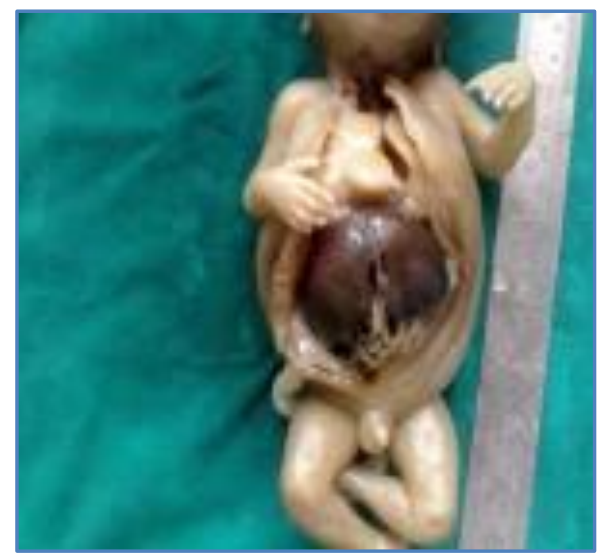

Figure 3.2

Fig. 3.3: PHOTOGRAPH- CUT SECTION OF CHEST SHOWING SOLIDIFIED LUNGS

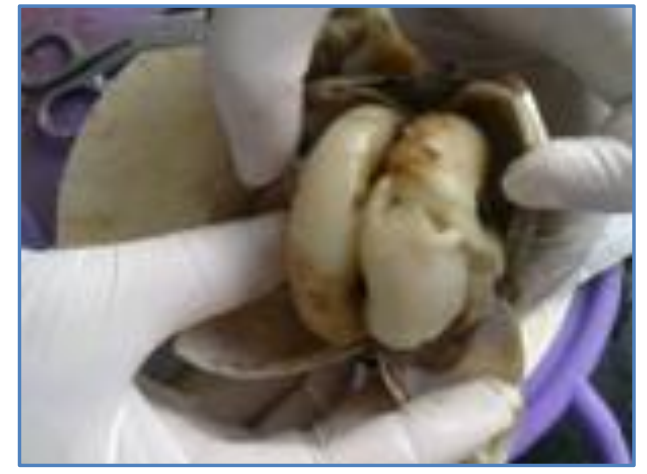

Figure 3.3

Fig. 3.4: PHOTOGRAPH SHOWING THE BULGED BLIND ENDING CARINA

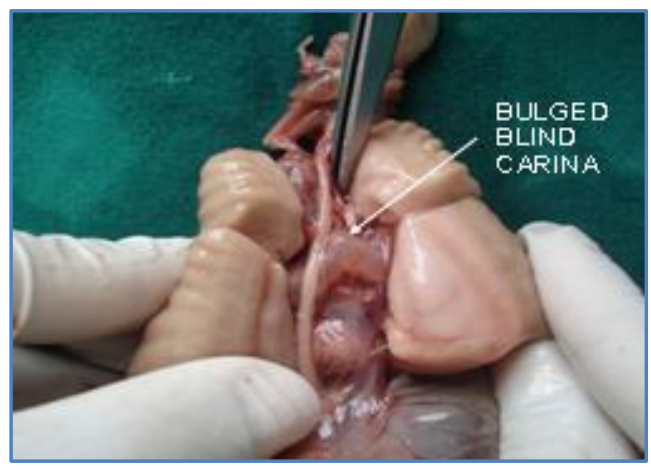

Figure 3.4 


\section{CASE REPORT}

Fig. 3.5: PHOTOGRAPH SHOWING THE BLIND ENDING CARINA

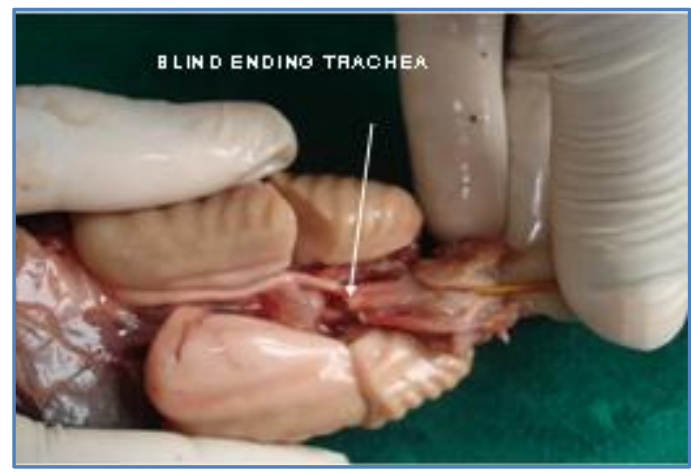

Figure 3.5

\section{HISTOPATHOLOGY IMAGES CONFIRMING CCAM (Fig. 4, 1-2)}

Fig: 4.1 \& 4.2 PHOTOGRAPH SHOWS THE SWOLLEN CELLS OF BRONCHIAL TREE

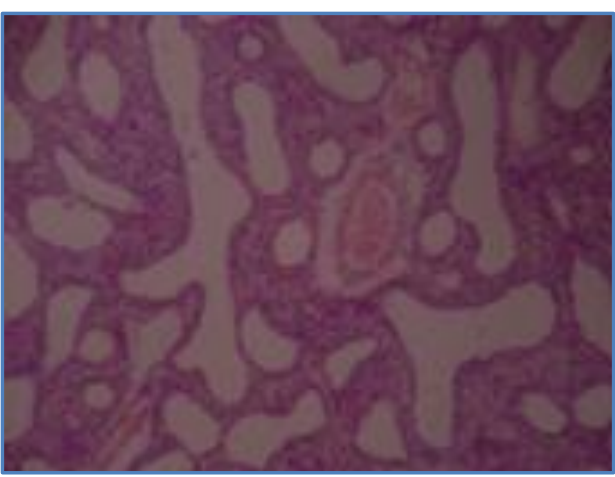

Figure 4.1

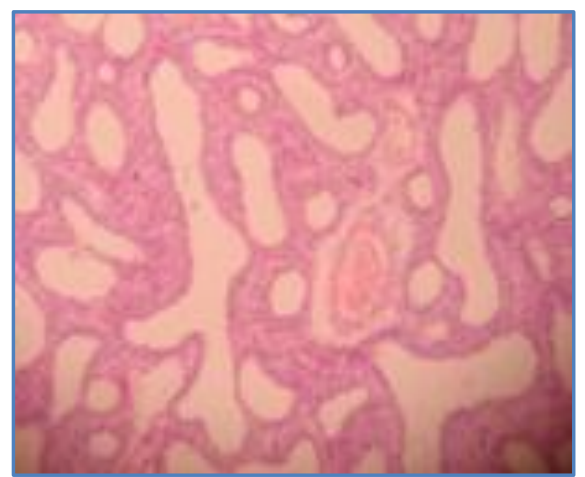

Figure 4.2

\section{REFERENCES:}

1. Hedrick MH, Ferro MM, Filly RA et al. Congenital high airway obstruction syndrome (CHAOS): A potential for perinatal intervention. J PediatrSurg1994; 29:271-4.

2. Balc $S$, Altnok G, Ozaltn F et al. Laryngeal atresia presenting as fetal ascites, olygohydramnios and lung appearance mimicking cystic adenomatoid malformation in a 25 -week-old fetus with Fraser syndrome. Prenat Diagn 1999; 19: 856-8.

3. Kalache KD, Franz M, Chaoui R, Bollmann R. Ultrasound measurements of the fetal trachea, larynx and pharynx throughout gestation and applicability to prenatal diagnosis of obstructive anomalies of the upper respiratory digestive tract. Prenat Diagn 1999; 19: 211-8.

4. Watson WJ, Thorp JM Jr, Miller RJ. Prenatal diagnosis of laryngeal atresia. Am J Obstet Gynecol $1990 ; 163 ; 1456$.

5. Lim FY, Crombleholme TM, Hedrick HL et al. Congenital High Airway Obstruction Syndrome: Natural History and Management. Pediatr Surg.2003; 38: 940-5. 


\section{CASE REPORT}

6. Kohl T, Hering R, Bauriedel G et al. Fetoscopic and ultrasound-guided decompression of the fetal trachea in a human fetus with Fraser syndrome and congenital high airway obstruction syndrome (CHAOS) from laryngeal atresia. Ultrasound Obstet Gynecol. 2006; 27: 84-8.

7. Kalache K, Chaoui R, Tennstedt C, Bollmann R. Prenatal diagnosis of laryngeal atresia in two cases of congenital high airway obstruction syndrome(CHAOS). Prenat. Diagn. 1997;17:577-81.

8. Öndero lu L, Karamürsel SB, Bulun A et al. Prenatal diagnosis of laryngeal atresia. Prenat Diagn 2003;2:277-80.

9. Kanamori Y, Kitano Y, Hashizume K et al. A case of laryngeal atresia (Congenital high airway obstruction syndrome) with chromosome $5 p$ deletionsyndrome rescued by ex utero intrapartum treatment. J Pediatr Surg 2004;39:25-9.

10. Vidaeff AC, Szmuk P, Mastrobattista JM, Rowe TF, Ghelber O. More or less CHAOS: case report and literature review suggesting the existence of a distinct subtype of congenital high airwayobstruction syndrome. Ultrasound Obstet Gynecol2007; 30:114-117.

11. Porat NG, Lipitz L, Orat MP, Achiron R. Prenatal sonographic diagnosis of upper airway obstruction a challenge can be achieved. J Laryngol Otol1966; 110: 583-585.

12. Tang PTM, Meagher SE, Kahan AA, Woodward CS. Laryngeal atresia: antenatal diagnosis in a twin pregnancy. Ultrasound Obstet Gynecol 1996; 7: 371-373.

\section{AUTHORS:}

1. Dinakara Prithviraj

2. Suresh A.

3. Anna Mariam Paul

\section{PARTICULARS OF CONTRIBUTORS:}

1. Associate Professor, Department of Paediatrics, VIMS \& RC.

2. Assistant Professor, Department of Radiology, VIMS \& RC.

3. Post Graduate, Department of Paediatrics, VIMS \& RC.
NAME ADDRESS EMAIL ID OF THE CORRESPONDING AUTHOR:

Dr. Dinakara Prithviraj,

Vydehi Institute of Medical Sciences and

Research Centre,

\#82, EPIP Area, White Field,

Bangalore - 560066 .

E-mail: drdinakar.nishanth@gmail.com

Date of Submission: 27/03/2014.

Date of Peer Review: 28/03/2014.

Date of Acceptance: 04/04/2014.

Date of Publishing: 28/04/2014. 